\title{
Understanding mobile application development and implementation to monitor Posyandu data in Indonesia: a 3-years hybrid action research to build "a bridge" from the community to national use
}

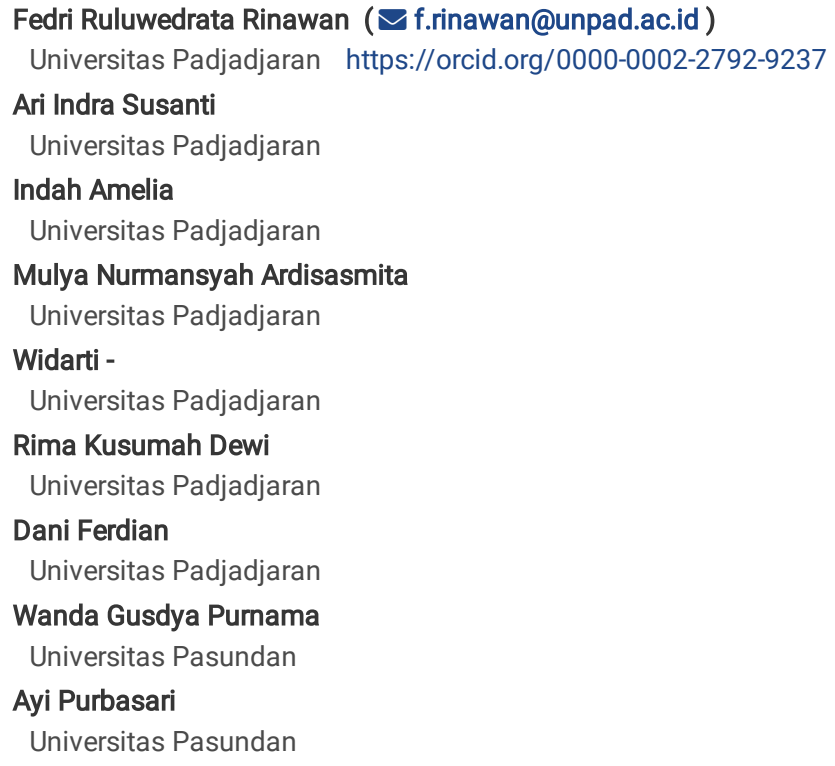




\section{Abstract}

Background. There is a small number of facts available to understand better how mobile health application technology on mother and child health (MCH) is developed. This study is aimed: (a) to explore the process of developing the mobile app in $\mathrm{MCH}$ community-based services in the Indonesian setting/ Posyandu, (b) to perform feasibility assessment among the community health workers (CHWs), and (c) to see the potential use of the mobile app in the country.

Method. Using a hybrid method in which the action research principles and the mixed-method, which comprise qualitative and quantitative methods, were synergistically combined for the end-users. The study was conducted in Pasawahan sub-district, Purwakarta, Indonesia, from 2017 to 2019 . Content analysis, coding, and categorizing were carried out using NVivo 12 Pro for the transcribed data. Wilcoxon Test (2018 and 2019) was conducted using STATA 15 Special Edition.

Results. (1) The use of a CHW notebook for data entry in the Posyandu information system book delayed the data reporting process, resulting in the need to develop a mobile app; (2) There are significant differences of CHW's knowledge $(p=0.000)$ and skills $(p=0.0097)$ on training (2018) and Posyandu phases (2019); (3) As many as 964 posyandu are registered to Posyandu mobile app from almost all provinces in Indonesia. Conclusions. The 3-years hybrid approach suggests the crucial phases to develop a mobile app in a more user-friendly manner to substitute the use of CHW's old-fashion book use and that its implementation is promising for national use.

\section{Background}

The Mobile health (mHealth) app technology practice in the health sector has been for public and generates more effective development $(1,2)$. However, its implementation may be complicated due to the issue of utility among the community health worker (CHW)/cadre of mother-child health (MCH) services in the Indonesian setting, known as the integrated service post or Posyandu (2). Action research that starts with a qualitative approach can be implemented to explore the feasibility of an android-based health application $(3,4)$. Recent systematic reviews suggest little evidence to understand better how the mobile health application tool is designed using the qualitative approach to enable the performance of the CHW in community-based mother and child health services (5-9). In 2019, some other recent literature review pointed out a lack of baseline data before the beginning of the evaluation and experimental studies regarding $\mathrm{CHW}$ and mHealth (10).

A qualitative approach in action research is crucial to construct a shred of foundation evidence to design an android-based application. It is conducted to explore the information on how to adjust and prepare the acceptability rate of the CHWs and mothers to the practice of new intervention where technical problems such as mobile network overage, internet access, and gadget maintenance may be challenging (11). To adjust the CHWs' work into a new improvement, understanding the principal to the technical scope of ideas from the previous activities in running Posyandu is essential. The Posyandu activities consist of 5 categories: registration, height and weight measurement, documentation, education, and healthcare (family planning, immunization). Based on the activities offered, Posyandu is divided into four levels, named in order of size, as follows: Pratama (performance of 5 Posyandu activities by less than $5 \mathrm{CHWs}$ in an irregular recurring interval), Madya (consists of Pratama + more than eight times of activities performance per year), Purnama (consists of Madya + independent community-fund with less than 50\% participants), and Mandiri (consists of Purnama + more than 50\% participants). During the registration, a national report form called the Posyandu Information System (PIS) book provided by the Ministry of Home Affairs must be filled by the CHWs and supervised by a village midwife. However, a long queue arises as another issue because the CHWs need to find mothers' and children's names to fill in the PIS book (12).

To resolve the issue of time constraints, the CHWs found an idea to write the mothers' and children's names and data in a book for a temporary purpose before rewriting them in the monthly and yearly national report. Later, after the end of Posyandu activities, they would enter the recorded data in the PIS book. However, the time-consuming data entry and reports process posed as another challenge for the CHWs due to the need for family time. Preparing a new intervention to support the CHWs could be done by exploring their point of view and habits in running the Posyandu. This intervention is essential because the $\mathrm{CHWs}$ have a central role in connecting the community and national level through healthcare providers in the Public Health Centers (PHC) that are distributed across the country (13). In Bahasa Indonesia, the term PHC is referred to as Puskesmas. The CHWs should provide a monthly report to connect between the community condition and Puskesmas'policy to decide the budget for the community health programs.

There are many mobile health technologies (mHealth) that have already taken place amongst low- and middle-income countries. For example, the use of mHealth can support $\mathrm{CHW}$ to deliver health care services $(8,11,14)$, community case management $(2,15)$, and health behavior interventions $(7,8)$. There is also a record of the use of mHealth by midwives collaborating with $\mathrm{CHWs}(16)$. Some studies identified mHealth use to help healthcare services for patients and families (6), including for palliative care $(17,18)$, which also highlights its pivotal role (19). A recent literature review proposes that data collection is the main challenge and that it should be included in CHWs' skills training to support many community programs by using mHealth (8) so that they may provide more effective support (20). The World Health Organization (WHO) and United Nations Children's Fund (UNICEF) recommend countries to increase the quality of care, monitoring, and assessment using innovative approaches, including maximizing the use of the handheld phone. A systematic manner of data collection, aggregation, analysis, and reporting from the smallest level of administration area (sub-national) to the national one is crucial (21).

Scaling up the CHWs' capability and supporting their data monitoring and reporting or evaluation within a flexible time to fulfill their role is a primary factor for sustaining the program in a community $(8,13)$. Then, identifying the key obstacles in its implementation is a continuing process $(22)$. It is promising to use mHealth because $\mathrm{CHW}$ can rapidly learn to use it as long as the local context is adjusted, such as the language and other user-friendly factors (16). A monthly report on the data extracted from the Posyandu Information System (PIS) is required for Puskesmas midwife. It includes those related to the nutrition data of infants to children under-5 years old, mother pregnancy, post-partum data include exclusive breastfeeding data and a couple in reproductive age. In this study, the PIS design on the intervention to ease the data entry and reports works was conducted based on the information acquired from the CHWs and mothers. 
Many strategies can be applied to motivate mothers to come to the Posyandu. Some of them include data monitoring of the nutrition status of babies and children under- 5 years old, immunization status including pregnancy mothers data, nutrition counseling by the $\mathrm{CHW}$ to $\mathrm{control} \mathrm{MCH}$ programs, and emphasizing the benefits of attending the Posyandu $(12,23)$. Data records and reporting are essential to store the data, which can be a basis of the evidencebased strategies and their effectiveness evaluation for the Posyandu. It can help the Puskesmas and village office to allocate the necessary budget to improve the existing prevention program, which will generate feedback for each program's outcomes. In a recent literature review, measuring the effectiveness of the $\mathrm{MCH}$ prevention intervention by the $\mathrm{CHWs}$ is a critical step for the $\mathrm{MCH}$ program of a country (20).

Data record and reporting by the CHWs in the Posyandu can be complicated in Indonesia. It is because of many services performed by the CHWs. Those activities include inviting mothers and their children or babies and approaching them when they are not coming to Posyandu. The CHWs are also communicating with sub-village and religious leaders as a form of community engagement to encourage mothers and children to come to the Posyandu. After requesting the participation of mothers and children/babies, the $\mathrm{CHWs}$ will manage the registration, measure the weight and height of the babies and children, record them in a data book, educate mothers and refer them and their babies to the village midwife for an immunization appointment, and so on. Data records and reporting workload need to be simplified. Critical problem identification should be conducted to be the basis of the initiation and development of solutions. This study is aimed: (a) to explore the process of developing the mobile app, (b) to perform feasibility assessment among the CHWs, and (c) to see the potential use of the Posyandu mobile app in the country.

\section{Method}

Action research consists of a step-by-step development that begins with an assessment to identify initial ideas, implementation, and feedback for improving the ideas. The process is an iterative cycle to support better action or intervention continuously. In this case, the assessment outcomes should meet the community needs to prepare the necessary implementation/intervention, which will help the CHWs in making a Posyandu data report. The information is vital to develop a plan to design an intervention starting from the initial blueprint. The intervention design and further action steps to deliver the intervention should also be presented to the community for the sake of improvement. The ideas and intervention are also required to prepare for the advocacy to relevant stakeholders, e.g., government and/or private sectors.

In general, the combination of action research principles and mixed-method (qualitative and quantitative methods), hereinafter referred to as 'hybrid approach', are synergistically applied for end-users. The core design is an exploratory sequential mixed-method design (24). This hybrid approach is deployed in 8 phases: (1) Determining issues by analyzing and understanding users' activities which refer to a process of exploring their activities at the Posyandu, (2) Making a prototype design blueprint, and (3) Evaluating design with the users through presentation and discussion. Any feedback will be a correction for step 2, which subsequently leads to step 3. Afterward, (4) Designing the prototype, and (5) Creating a dynamic design prototype or a dynamic design that is programmed with planned features but still not in the executed form. Subsequently, (6) Evaluating design with the users to prevent any miscommunication, (7) Testing the executed prototype, and (8) Implementing the final version of the graphical user interface (GUI). Graphical user interface design is an activity to ensure that a good user interface program design is complimented with good quality of the program. It spots interaction between the user and apps using graphical information or visual widget, for example, text boxes and clickable buttons. An approach is needed to bridge the quality and user's needs. Hence, it can be easier to be accessed by the user (25). The initial action research is conducted in a qualitative approach because the community insight must be developed after the observation of information. Thus, the GUI can fulfill the needs of the community. In phases 1 to 3 , the qualitative design is used for phase 4-5. Then, in phase 6 to 8, the mixed-method (embedded quantitative-qualitative approaches) design is employed to identify the end users' knowledge and skills, including their feedback in using GUI in the application (Figure 1).

In practice, the eight phases are explained more as the prototyping stages of the app. We implemented a user-centered design when starting the development from low to high fidelity persona. The stage cycle was iterative, in which we identified the context directly from the users. After that, we explained it in technical terms and the programer used these as a reference for the improvement. When developing a low fidelity persona, we started with a qualitative study to prepare the paperwork to create a blueprint. A Focus Group Discussion (FGD) for the CHWs and mothers were organized to discuss about their activities in Posyandu, the importance of mHealth, and the app's main list of features (box 1 in figure 1). The first iterative cycle began with a blueprint (box 2 in figure 1 ) created based on the FGD, and then we went back to them to present it. They gave us some feedback (box 3 in figure 1), followed by the approval on the improved blueprint (box 2, iterative) before the development of the first high fidelity persona in the android package (APK) form (box 4, figure 1).

The first APK was then sent to them, and then they installed it as a trial version to use in training. Once they used it, we observed them and organized a FGD regarding the use of the trial version in training (box 3 , iterative). Then, the feedback we received was used to improve the trial version (boxes 2 to 4 , iterative) into a more dynamic solution prototype (box 5 figure 1). The dynamic prototype was a start for the second iterative cycle. The evaluation was performed using the FGD. This prototype was dynamic in its change and improvement, depending on the iterative cycle process based on the number of feedback from the users (box 6). Once it received the users' approval, it was then executed and launched in Google Play (GP) (box 7). This executed prototype was not the final version, even though we already launched it on GP. It was still an unreleased version and could be downloaded from GP. Before confirming the final GUI (box 8 ) to release the final version, the iterative cycle is crucial for a better development. We also conducted the observation as well as another FGD for CHWs on the use of the app's unreleased version when running the Posyandu. We took into consideration the received feedback as a reflection to develop the final GUI of the app (box 8 of figure 1).

For the qualitative research, we established FGDs of 6-15 informants, which included the CHWs and mothers in 2017, the CHWs in 2018, and the CHW and Midwives from each village in 2019. This method was implemented because these populations engaged more at the Posyandu and were able to use smartphone mobile app technology. Midwives had a role as Posyandu supervisor in each of villages. The research was conducted in Pasawahan sub-district, Purwakarta district, West Java province, Indonesia. We interviewed the FGD informants by using open questions about the challenges when running the Posyandu to understand their concerns and propose an adequate solution. Then, the input was considered and followed by the users' feedback when the 
solution was implemented. The qualitative sample was chosen by using a purposive sampling technique according to their activity and ability to use a smartphone. The illustration for this explanation is provided in Figure 2.

To enable the cadres to operate Posyandu mobile app, an instruction/user guide training was required. The qualitative data was acquired by implementing the FGD with the Posyandu cadres to explore their opinion on the Posyandu mobile app instruction. The FGD was conducted with 12 Posyandu cadres representing each village in the Pasawahan sub-district. The information acquired was used to establish a Posyandu mobile app guide needed by the cadres. After the user guide creation process was completed, it was then delivered to the cadres as a reference during the training.

After that, the quantitative data was collected to assess the cadres' knowledge and skills in using the Posyandu mobile app during the training. Knowledge consists of content about account registration management, benefit of the app, pregnant mother identity and physical examination information, under-five identity and physical examination information, and the Posyandu information system. Skill consists of account registration, application log in, fill in baby and toddler data, display for baby and toddler data, search for baby and toddler data, fill in baby and toddler examination data, display for baby and toddler data, fill in pregnant women data, view pregnant woman data, search for data on examination results of pregnant women, and log out. These are detailed in the Supplemental Tables 3 and 4. The knowledge assessment was conducted using questionnaires, while the skill assessment was conducted through a quantitative observation by using a checklist. During the observation process, the researchers were assisted by selected ten cadres (those who were most active and trained) to be facilitators.

The facilitators were trained in using Posyandu mobile app based on the instruction book. Each facilitator should be able to operate the Posyandu mobile app and to guide the cadres on how to use Posyandu mobile app. Each facilitator was provided with an android/tablet and in charge of 8-10 cadres. The facilitators organized a visit schedule to the cadres under their responsibility. For a month, the Posyandu cadres were guided by the Posyandu mobile app implementation trainer using the provided tablet/handphone in rotation.

The quantitative research sample size was counted based on the objective to test the significance between groups and between two points of time (training time and implementation at Posyandu time). We used per group sample equation from Hulley SB et al., 2007 using a 0.05 (two-tailed hypothesis), $\beta 0.10$, effect size from previous research $0,56(26,27)$, resulting in a number of 72 to 86 respondents $(28)$. The treatment group consists of the cadres who fulfilled the inclusion criteria (active cadre) and participated in the Posyandu mobile app training for one day with an instruction book and guided by a trained cadre facilitator. The control group consists of the cadres who fulfilled the inclusion criteria and only participated in the one-day training. The knowledge and skill assessments were conducted one month after the training (2018) and during the implementation of Posyandu (2019)

To see the impact of the local use to national use, we released the application on Google Play in December 2018. We analyzed the distribution of registered Posyandu on the mobile app in the country. We used our admin website to download the excel file comprising all Posyandu that have registered to the Posyandu mobile app and registered the data in one database server. First, we checked the data quality using STATA version 15.1 Special Edition License. Then, to make a distribution map, we used QGIS version 2.6 (open source) shapefile of 34 provinces in Indonesia to map the registered Posyandu until 31 December 2019.

\section{Analysis}

In the qualitative analysis, we coded and categorized the answers of mothers and CHWs on problems when running Posyandu mobile app and recommendations to sustain its operations and to improve its efficiency. We categorized similar answers to a node/code and used the grouping's insight to name the node. We intended to build and understand the critical connection between the needs and recommendations to be used as feedback to the mobile health application design. The analysis used content analysis nodes in NVivo 12 Pro License. The context of the diagram and entity relationship diagram was extracted from the application program maker software. Subsequently, the results were exported and, therefore, could be displayed as a report. As for the quantitative data analysis, we used STATA version 15.1 Special Edition License to observe the significance of implementing the T-Test dependent or Wilcoxon Test as an alternative if data was not normally distributed. We also analyzed the effect by looking at the $Z$ score (standardized test statistic, produced by STATA) divided by $\sqrt{ } \mathrm{N}(\mathrm{N}=$ number of all respondents) and time difference (training time, 2018, and implementation time, 2019)(29).

\section{Results}

\section{Data Flow Diagram Result in the Database}

Scope of the System

Posyandu information system is a system which is developed to support Posyandu data management and analysis. The collected data was recorded by the $\mathrm{CHWs}$, which includes the username and password, mother's identity, pregnant mother's identity, physical examination of a pregnant mother, under-five identity, and physical examination of under-five. This information could also be seen by the CHWs in the monthly report section of the application. The form was already categorized into a monthly and yearly national form. Meanwhile, parents could see the information about their under-five children by performing the following steps: registering username and password, login, and choosing their children's data, which were already recorded by the CHWs. Afterward, other information that could be accessed by the parents includes their identity, physical examination (of a pregnant mother), their children's identity and physical examination, as well as mother and child health book. The information is depicted in Figure 3.

\section{Initial Phase Qualitative Research Result (2017)}

The first result consists of the qualitative part of the study, where the input collected from the CHWs and mothers are combined in one table and divided into themes, key insights, and quotes. The Supplemental Table 1 shows the main problem faced by the CHWs, which is unorganized yearly data record and 
reporting. They stated that the data was manually hand-written in their notebook. It was easier for them than to write immediately to the big book report, or Posyandu information system (PIS) book, where one of them confirmed that "the paper notebook can be used immediately." Another informant also ascertained that, "if the data is written directly to the PIS as the mothers come, it will make my head blown (since it is) confusing." The CHWs also did not have time to put children's names in an orderly manner, as suggested by one of the informants. Then, the issue of delay to report to the Puskesmas was also present. This was due to the double burden: data entry to their personal book and report entry to the big book. The CHWs felt that they had to write more redundant works. A worker stated in the FGD that, "(...) we have to write the names to the Posyandu information system book in an orderly manner." They indicated that they required a solution such as mHealth application to facilitate the data recording and reporting process. The CHWs described it as, "(something) like a tool, but it can be re-accessed, like an archive. Because we need it when Puskesmas requests (a report), sometimes it can be accessed again."

As for the mothers in Supplemental Table 1, the app would help them supervise their under-five children's growth and development. The mothers quoted that, "(We) need to know our child's development so that we can monitor by ourselves for our child.". Moreover, working mothers need to monitor their children's growth while their family or neighbor were in charge of taking care of them to Posyandu. One mother said, "For example, this (child), the child is taken care of by another person (because) the mother is working." They expected not to have to ask the CHWs for a few times to know about their children's growth, because "(it was) just not practical." It is suggested that mothers need Posyandu mHealth application "so that we can look at it privately (and immediately). Thus, we do not have to ask the CHWs continuously".

The activities, including the quoted difficulties above, act as the input to extend the context in the blueprint of the app. Besides, other inputs such as the registration, connection with children's data, data entry that can also have automatic report output in governmental form, child growth graph, and automatic alert of child growth were also recorded. The main list of features is depicted in the Supplemental Table 1.

Figure 4 illustrates the initial phase of the mobile app for $\mathrm{CHWs/cadre} \mathrm{and} \mathrm{mothers} \mathrm{using} \mathrm{the} \mathrm{touch} \mathrm{screen} \mathrm{smartphone.} \mathrm{In} \mathrm{the} \mathrm{beginning,} \mathrm{the} \mathrm{application} \mathrm{for}$ $\mathrm{CHW}$ and mothers differs in the registration menu. Quoted from one of the informants, "First, we click on the Posyandu app, then we register in it, after that we click it once more, then we are connected to our children's data." Mainly, personal data and the name of the nearest Posyandu were needed in the registration before they could logvin according to their role as a cadre or a mother.

Table 1. Number of participants in each phase of the study

\begin{tabular}{|l|c|c|c|c|c|}
\hline \multirow{2}{*}{ Participants } & \multicolumn{5}{|c|}{ Number of participants in each phase year } \\
\cline { 2 - 6 } & 2017 & \multicolumn{2}{|c|}{2018} & \multicolumn{2}{|c|}{2019} \\
\cline { 2 - 6 } & Qualitative & Qualitative & Quantitative & Qualitative & Quantitative \\
\hline CHWs & 13 & 12 & 171 & 10 & 156 \\
\hline Mothers & 14 & & & & \\
\hline Midwives & & & & 11 & \\
\hline
\end{tabular}

\section{Middle Phase Qualitative Research Result (2018)}

Table 2 illustrates the qualitative theme and key insights that emerged during the training in 2018 , as indicated in the table. The cadre recommended that the notification feature on the monthly weight data should be automated. Height was measured according to government and WHO guidelines. However, they confirmed that, "We do not measure the height monthly but only once every several months." After the cadres enter the required data, they wanted to see the online information on whether the under-five growth chart was increasing or decreasing automatically. Also, the expected the information to be available anytime. To quote, "We want it to be like (...) online reporting, so we do not need to measure the number of decreases." (Supplemental Table 2). By doing so, they expected that the app would ease their duties in Posyandu by recording the data and, at the same time, submitting the report to the Puskesmas directly. Nonetheless, when imagining if the app were used in Posyandu, sometimes they still felt confused about some obstacles, "A while ago, some data was successfully stored, but some was unsuccessful." They estimated that the posyandu situation would be unsupportive when it was crowded, "During the Posyandu working day, it will remain crowded so that the data entry will be done after the end." They also worried about the internet quota availability when they ran out of money.

Considering the pros and cons, the cadre still believed that the app could be a great assistance for them. The learning process played as a central role. During the training, they stated that, "We think we can use it because we are used to using and playing with a handphone. However, before that, the application should be made available first." The app was available during the training but in the APK form and we had not published it yet on Google Play (GP) at the time. In the late 2018, we launched it on GP to make it more available and accessible. During the learning process, they needed more written information in the form of a guidebook. The cadres also coordinated with the village officers regarding the solution of any app-related issue. One of the issue was related to the internet quota, where it was stated that "(...) the Posyandu does not have any budget (to cover it). I asked the villagers about the internet quota fee and they already shook their heads." Regardless, it was expected that the cadres could use the app and put them into practice at the Posyandu after the training was ended. They also expressed their interest on using the app, "If using the application if possible, then so be it, (I) cannot wait to use it." More information regarding the feedback can be seen in the Supplemental Table 2.

Table 2. Theme and Key Insight from 2018 Analysis 


\begin{tabular}{|c|c|c|}
\hline No & Theme & Key Insight \\
\hline 1 & Under-five Data Input & $\begin{array}{l}\text { a. Under-five body weight measurement } \\
\text { b. Under-five body height measurement time } \\
\text { C. Under-five body height measurement according to WHO }\end{array}$ \\
\hline 2 & Under-five Data Display & $\begin{array}{l}\text { a. Under-five data can be accessed anytime } \\
\text { b. Under-five measurement result display } \\
\text { c. Parents can access under-five data }\end{array}$ \\
\hline 3 & Posyandu Mobile app Components & $\begin{array}{l}\text { a. Posyandu mobile app menu } \\
\text { b. Online report }\end{array}$ \\
\hline 4 & Benefits of Posyandu Mobile app & $\begin{array}{l}\text { a. Posyandu reporting and recording is easier than the big book report } \\
\text { b. Facilitate cadre's duties in Posyandu }\end{array}$ \\
\hline 5 & Obstacles in using Posyandu mobile app & $\begin{array}{l}\text { a. Confused/need to adapt } \\
\text { b. Unsupportive Posyandu situation }\end{array}$ \\
\hline 6 & Learning process & $\begin{array}{l}\text { a. Cadre's knowledge of Posyandu mobile app } \\
\text { b. Cadre's skills on the use of Posyandu mobile app } \\
\text { C. Cadres need more training about the app }\end{array}$ \\
\hline 7 & Posyandu mobile app guidebook & $\begin{array}{l}\text { a. Significance of Posyandu mobile app guidebook } \\
\text { b. Guidebook format } \\
\text { c. Guidebook size } \\
\text { d. Guidebook writing style } \\
\text { e. Images in the guidebook }\end{array}$ \\
\hline 8 & Information in the guidebook & $\begin{array}{l}\text { a. Instruction } \\
\text { b. How to register an account/log in } \\
\text { c. How to input Under-five data } \\
\text { d. How to input pregnant mother data }\end{array}$ \\
\hline 9 & Cadre's expectation & $\begin{array}{l}\text { a. Tablet/HP provision } \\
\text { b. Use of application in Posyandu }\end{array}$ \\
\hline 10 & Cadre's worries & a. Internet quota availability \\
\hline
\end{tabular}

\section{Final Phase Qualitative Research Result (2019)}

Table 3 below demonstrates a few feedbacks from the cadres and village midwives on the development of the application version. Tables 3 and 4 incorporate the ideas from the cadres and midwives in separate FGDs. When using the app during the Posyandu activities, some corrections would be required, as quoted from one of the informants "Here, the name of my village in this application is wrong." Other feedback recommended to insert a photo in the account information and an alternative password. As a supervisor of cadres in several Posyandus, one of the midwives suggested that, "(...) in the future, it would be great if there is an access for the Village Midwife and not only for the cadres.", which would bring a positive impact for the next app development. Creation of a website was also discussed for the reporting purpose. The midwives perceived that reporting with a laptop would be easier than with a handphone. More feedback is depicted in Table 3.

Table 3. Cadre and Village Midwives FGD Result on Posyandu Mobile app Development 


\begin{tabular}{|c|c|c|c|}
\hline No. & Theme & Key Insight & Noteworthy Quotes \\
\hline 1. & Identity & $\begin{array}{l}\text { Village name } \\
\text { correction in the } \\
\text { editing menu }\end{array}$ & "Here, the name of my village in this application is wrong." \\
\hline \multirow[t]{3}{*}{2.} & Account & $\begin{array}{l}\text { Account owner } \\
\text { photo }\end{array}$ & $\begin{array}{l}\text { "Ma'am, can't we put our photo so that there will not only be our name (displayed) in it? Even Google mail has the owner's } \\
\text { photo. This will result in a higher sense of belonging." }\end{array}$ \\
\hline & & $\begin{array}{l}\text { Alternative } \\
\text { password }\end{array}$ & "Oh, I forgot the password. It is not possible to login. It would be great if an alternative password exists." \\
\hline & & $\begin{array}{l}\text { Individual } \\
\text { account for } \\
\text { Village Midwife }\end{array}$ & $\begin{array}{l}\text { "That is, in the future it would be great if there is an access for the Village Midwife and not only for the cadres. So, it will not be } \\
\text { a hassle to enter (the data) one by one. Now, there is only } 5 \text { Posyandu in one village in different locations, and one single Village } \\
\text { Midwife handles even } 13 \text { Posyandu." }\end{array}$ \\
\hline 3. & Website & Web creation & "We hope that there will be a Web to monitor at a larger scale for the Midwife. The Web can make it easier to read the report." \\
\hline 4. & $\begin{array}{l}\text { New } \\
\text { menu }\end{array}$ & $\begin{array}{l}\text { Pregnancy age } \\
\text { automatic } \\
\text { calculation }\end{array}$ & $\begin{array}{l}\text { "It is hoped that after the input of the first day of the last period, the pregnancy age will be automatically calculated in the next } \\
\text { examination schedule." }\end{array}$ \\
\hline
\end{tabular}

We analyze the advantages and disadvantages of the implementation of this application, as indicated in Table 4 from the side of the user, organization, technology, and environment.

Table 4 illustrates the resistance of some cadres to change their behavior from paper-based to digital-based services. In practice, the village midwives assisted in supervising and motivating the implementation of the app during the Posyandu activities. Continuous organizational support from the village was vital in 2019 as shown by the research results depicted in Table 4, which was also applicable in the previous year. Standard operating procedure (SOP) was essential to be issued by the government, which should address the leadership of the village office, subdistrict, Puskesmas, and district health office (DHO). The SOP would strengthen the implementation of the app even though there would be a double work burden at the beginning of the change, which would disappear once they were already accustomed by it.

Table 4. Advantages and Disadvantages Analysis of Posyandu mobile health application 


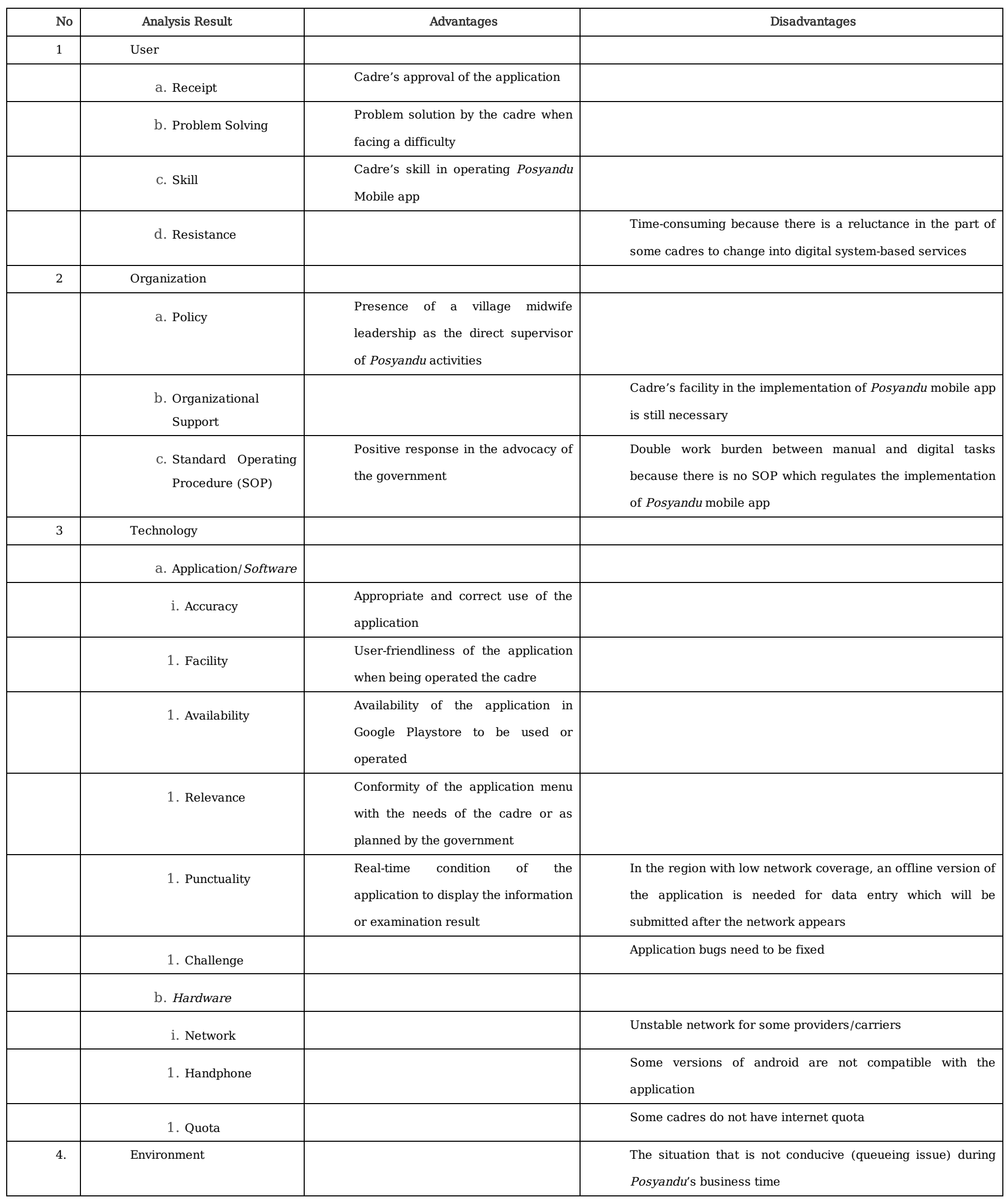

Also, technology is the core part of this implementation. Software and hardware analysis are crucial. In 2018, the app was submitted and launched on Google Play (GP). In 2019, it was available in the GP store of android handphone to be downloaded and operated. The app answered the users' needs as identified in the previous years of action research, such as real-time data entry and report. However, in the region with low network coverage, an offline version was still 
needed for the next app development. Thus, the data submission could be made after the network was available. Some handphones found that the unstable network issue persisted, while other phones were not compatible with the app version. It was crucial to continuously improve the version to make it more compatible with all phones.

Evaluation of the cadre's knowledge and skills in the implementation of Posyandu mobile app during the training (2018) and Posyandu activities (2019) were conducted as an ongoing research.

The respondent characteristics are shown in Table 5. The majority of the respondents was more than 35 years old, and most of them received secondary level of education or Junior High School). In 2018, the respondents consisted of 171 Posyandu cadres. We found a decline of $8.77 \%$ in 2019 . The reason for this was because some respondents were no longer reachable and could not be followed up. Both groups consisted of 15 people. The rest of the respondents could be evaluated up to 79 people in the treatment group and 77 in the control group. Hence, the total number of respondents that could be assessed was 156 people.

Table 5. Respondent Characteristics in Pasawahan Sub-District, Purwakarta District 2018 and 2019

\begin{tabular}{lcccc}
\hline \multirow{2}{*}{ Characteristics } & \multicolumn{2}{c}{2018} & \multicolumn{2}{c}{2019} \\
\cline { 2 - 5 } & Treatment & Control & Treatment & Control \\
& $(\mathrm{n}=86)$ & $(\mathrm{n}=85)$ & $(\mathrm{n}=79)$ & $(\mathrm{n}=77)$ \\
\hline Age (year) & 18 & 22 & 16 & 19 \\
$26-35$ & 32 & 33 & 31 & 33 \\
$36-45$ & 36 & 30 & 32 & 25 \\
$46-55$ & & & & \\
Education & & & & \\
Elementary School & 24 & 31 & 21 & 26 \\
Junior High School & 32 & 33 & 30 & 30 \\
Senior High School & 30 & 21 & 28 & 21 \\
\hline
\end{tabular}

The comparison between the knowledge during the training (2018) and the implementation of the Posyandu application (2019) is shown in Table 6.

Based on the Table 6, the knowledge and skills level of the cadres during the training and Posyandu activities have a significant average score difference equals to the value of $p<0.05$. This score shows that there is a difference in knowledge and skills between the training period and the performance of Posyandu activities. The effect of knowledge and skills were 0.34 (medium) and 0.21 (small), respectively, according to Cohen (29, 30).

Figure 5 illustrates provincial distribution across 34 provinces in Indonesia until 31 December 2019. As many as 964 posyandus were registered to Posyandu mobile app from almost all provinces in Indonesia. The highest number recorded was in the study area, which was in West Java (34.54\%). The rest was in other provinces that shown their interest in registering their Posyandu. After West Java, we identified Belitung, Jakarta, Central Java, and Yogyakarta in an orderly manner from the highest number of registrations. There was no registration from North Kalimantan and Maluku at the time.

Table 6. Comparison of Knowledge and Skills during Training and Posyandu Activities

\begin{tabular}{llccccc}
\hline \multirow{2}{*}{ Variable } & Occasion & \multicolumn{3}{c}{ Value } \\
\cline { 3 - 6 } & & Min & Max & Mean & P-Value & Effect \\
\cline { 3 - 6 } Knowledge & Training & 84 & 100 & 94.69 & $* 0.0000$ \\
& Posyandu Activity & 76 & 100 & 91.91 & $* 34$ \\
& Training & 7.69 & 100 & 85.63 & 0.0097 \\
& Posyandu Activity & 27.63 & 100 & 93.05 & \\
\hline
\end{tabular}

*Wilcoxon signed-rank test

\section{Discussion}

Starting qualitative research as a part of the action research is a crucial step to create a basis. Thus, it can develop an intervention that fits with the community problems and adjust their knowledge and skills (31). Some researches started formulating an intervention directly based on their initiative without involving the mindset of the targeted community (32). This practice will engender a potential bias when performing the intervention. It can be in the form of a knowledge bias in the sense of a gap between the intervention maker or expert-driven method (which is a top-down maker) and the end-user of the intervention (32, 33). Creativity in creating mobile health intervention should begin not only through a theory-driven process but also by exploring information from the end-user in terms of the targeted community (34). Then, the intervention designer should build details of the intervention design based on the explored information from the users (35). The

Page 9/16 
previous researches compared different top-down and bottom-up applications, where it was revealed that a bottom-up application was more effective in the community (32). Generally, the hybrid approach (Figure 1) consists of an exploratory sequential mixed-method design which begins with the qualitative research, then followed by the quantitative research. The incorporation of the action research into the mixed-method is in the sense of a cyclical improvement. For example, by quantifying the significance of the implementation effect (quantitative part), which will render it more efficient and useful for the next improvement (action research). This effect can be accompanied by the qualitative research embedded with the quantitative research in the view to extend the context of the reasons underlying the quantitative research results (36).

The application procedure in 2017 is considered as satisfactory if it is established and displayed based on the community feedback because the culturally embedded factors are essential to be explored (37). In the context of this research, the Posyandu cadres and mothers are related in the data flow diagram (DFD), which is the 'kitchen' or back-end of this application. DFD consists of what the cadres and mothers do and what they get from this application. From the previous researches, it is understood that building an application based on the feedback of the application user candidate will juxtapose the user's local context usage perception gap to the designer to support the community's adaptation and acceptance (38). The mobile app technology design can support more benefits in the establishment of strong partnerships between stakeholders to leverage the community capacity and empowerment, e.g., CHWs and mothers $(39,40)$. Empowerment needs a capacity building to maintain the $\mathrm{CHWs}$ ' and mothers' knowledge and skills to perform screening in the community (41). It is also stated in our research in 2018 about the needs in the learning process (Table 2). The smartphone we used was a touch screen smartphone because it can support the learning process. It corroborates with previous recent literature reviews which point out that it is better to use touch screen handphones due to its comfortable use and minimal need for technical support (11). However, our follow up after the training showed that there was in a medium effect on knowledge and small effect on skills. It differs from the result of another study that employed training intervention to $\mathrm{CHWs}$ by using a module in reproductive health and Tuberculosis fields which demonstrated that there was a large effect. Even though the fields are different, the idea of emphasizing the confidence and satisfaction of CHWs proposed by the study remains essential and relevant (42). In future, it is suggested to improve the training by empasizing such insight as well as considering different measures to reach a larger effect in 6 to 12 months (43). The good impact is that the CHWs will engage more in the intervention and benefit the society and the government (44)

Although, in general, the cadre's knowledge and skills in the Posyandu mobile app implementation have reached expectations, the implementation of a new information system is not easy because there are many influencing factors to be considered. The first factor is the user, where the implementation of a new information system will be successful if each user has a similar performance expectation that Posyandu mobile app can ease their work burden. Performance expectation is a strong predictor of information system utilization interest (45-47). Another factor is the usage facility, which is defined as when an individual feels certain that using the system does not require any extra effort $(48,49)$.

By using a personal handphone, the cadre feels more freedom to learn Posyandu mobile app; thus, there is more time for the cadre to learn to operate it. The increase in the cadre's skills is possible because the cadre performs independent learning. Although the cadres only received some information at the beginning and had to learn to operate the application independently, they had similar knowledge and skills with the group of cadres which received specific training. This independent learning is in line with the previous South African research in 2018 , where the explorative study demonstrated that the respondent assessment value dramatically increased. However, no intervention was given in the research. The interview result showed that the cadres often gathered and created bigger study groups in order to learn together (42). In the further action research, the quantitative research can be performed to objectively evaluate video education that is embedded as part of the mobile app. This research can also be continued by monitoring the steps to identify the development of the cost-effectiveness to strengthen a strong partnership when we do advocacy programs to different stakeholders (50).

In the Indonesian health system, access to screening in Posyandu, which is performed and documented using Posyandu mobile health application by trained $\mathrm{CHWs}$, can powerfully help the government to improve the data management and, thus, the quality of information. The village midwife, nutrition, and health promotion staffs of Puskesmas have a role in providing assistance to the activities of the cadres, including to validate the data of the Posyandu before reporting it to the Puskesmas (51). For example, the integration with government programs in the conceptual framework of stunting reduction interventions. There are five pillars of intervention, namely (1) commitment and vision of leadership, (2) national campaigns and behavior change, (3) convergence of central, regional and village programs, (4) food and nutrition security, and (5) monitoring and evaluation. In the fifth pillar, the stunting reduction intervention data management system requires an effort to bridge the data management at the village to district/city level up to the national level (52). An example of application which is available at the national level is the integrated nutrition information system (Integrated Nutrition). The Integrated nutrition data collection starts from the weighing and measurement data which is carried out every month at the Posyandu and recorded in the register book. Data entry to the information system falls under the responsibility of the Puskesmas which can be done at the Posyandu level as a source of growth monitoring data (53). However, we found that the implementation of data entry on the Integrated Nutrition application in the study area is still carried out by Puskesmas staff based on the results of measurements made by health cadres in the Posyandu. This can cause problems such as delay in inputting data due to the high workload of the Puskesmas staff. Therefore, an application is needed to be able to solve such issue (9). Our application can bridge the above-mentioned problems through a data input process that is directly carried out by health cadres during the Posyandu's working days. Then, the data can be directly downloaded by the Puskesmas, verified, and directly uploaded according to the integrated nutrition application format. In this way, the reporting process can run in a timely manner and can be used as a material for decision making process related to the efforts to reduce stunting.

The advantages of using mobile health for cadres are supported by our study and also by recent literature reviews $(6,9-11,50,54,55)$. Studies that have evaluated the program results demonstrate some evidence that mobile health application ( $\mathrm{m}$-health) assisted the community health workers in enhancing the provided treatment quality, services efficiency, and program monitoring capacity (5). Besides, similar research also reveals that m-health application is considered as beneficial for the community health workers because it can help with their duties, support clinical decisions and send instant data and feedback on the performance (56). Another finding indicates that mobile-based data collection increased the data collection punctuality, decrease the error level, and enhance the data completeness (8). 
Nevertheless, our study also found disadvantages such as user resistance, low organizational support, lack of standard operating procedure, low network coverage punctuality, bugs, and hardware challenges, as well as non-conducive environment (Table 4). Both advantages and disadvantages can help health promoters to plan continuous improvements in mHealth interventions(57). In general, the CHWs' role in the use of mobile technology is related to collecting field-based health data, obtain warning and reminder on routine Posyandu activities, facilitate health education sessions, and conduct a person-to-person communication with parents. A programmed effort from the cadres can strengthen health services performance (44), which focuses on community-based mother and child health management for the primary and secondary health prevention. The sense of doing is in line with another study about community case management on children's illness (15) but different in some settings of the task. The Posyandu's CHWs in our study mainly educate healthy people and refer immunization to the village midwife (primary preventions). They also educate at-risk people and perform screening through physical examination (e.g., measuring weight, the height of under-five), which are recorded in the Posyandu app (secondary preventions). If the cadre found an individual with a suspected illness such as malnutrition or fever, they will contact the village midwife and then refer the case to the Puskesmas. A leadership and management practice should be emphasized by the local government to support and motivate them to perform these tasks (58) to support a good start of the Posyandu information system through the app and its integration to the national information system. Good leadership, communication, and coordination will engender a robust health information system in Indonesia (59).

\section{Conclusions}

A hybrid approach is an essential and meaningful step in providing the basis of an intervention to fit with the community needs concerning the Posyandu services on data record and reporting. This 3-years hybrid approach with a user-centered design suggests the ideal phases in providing the basis to build a mobile app. The application can be created in a more user-friendly manner, replace the CHWs' old-fashion book use and build "a bridge" between the community and the national levels. In practice, the Posyandu application that we developed is promising to answer the problem of delay in the existing national reporting system. The cadre can contribute to the Posyandu information system by immediately entering the data in real time. Thus, it can automatically send reports faster to the Puskesmas and district health office.

This research also found that the cadre's knowledge and skills demonstrated a moderate and small improvement, respectively. Yet, both are necessary for the cadre during the performance of Posyandu services in the field. Short dissemination of information followed by continuous monitoring, independent learning, and user-friendly application will result in a satisfactory increase of the cadre's knowledge and skills. The result may be equally satisfying for both the group of cadres that receive training and the one that performs independent learning by using the Posyandu mobile app. For further development, new education video in the application on how to use the application is recommended to replace the role of direct or face-to-face dissemination of information.

As the limitation of this study, it did not involve the emphasis the need to increase the confidence and satisfaction of the CHWs when using the Posyandu app. If both aspects are taken into consideration in the future, it may extend the cadres' knowledge and skills more effectively than the result of the current study.

\section{Abbreviations}

CHW: community health worker/cadre; MCH: mother-child health; PHC: Public health centre; PIS: Posyandu information system; FGD: focus group discussion; IT: information technology; SOP: standard of procedure; DFD: data flow diagram

\section{Declarations}

\section{Ethics approval and consent to participate}

The ethical committee board of the Faculty of Medicine, Universitas Padjadjaran and Purwakarta district officials in West Java, Indonesia have approved the proposal of this research. During the research period, we asked for the informants and respondents' informed consent after we explained about the research. The informant (qualitative) and respondent (quantitative) who agreed and signed the consent continued to be part of the research. We also provide explanations regarding the privacy information before the users' approval in the app.

\section{Consent for publication}

Not applicable

\section{Availability of data and materials}

The dataset supporting the conclusions of this article is not publicly available due to confidentiality but is available on a reasonable request.

\section{Competing Interests}

The authors declared no potential conflicts of interest concerning the research, authorship, and/or publication of this article.

\section{Funding}

The authors disclosed receipt of the following financial support for the research and/or publication of this article. This research was funded by Lecturer Competence Internal Grant of Universitas Padjadjaran, Indonesia, PT Astra International Tbk, Indonesia Endowment Fund for Education, abbreviated as LPDP (Lembaga Pengelola Dana Pendidikan), Ministry of Finance, and Kreasi Insani Persada Foundation. The funders had no role in the study design, data collection, analysis, and preparation of the manuscript. 


\section{Authors' contributions}

F.R.R, A.I.S., and I.A performed the process from 2017 study design, data collection, data quality, and manuscript preparation; M.N.A. extracted the DFD design from the server and its explanation in the manuscript; F.R.R, W, and R.K.D. were involved in study design, data collection, data quality, data analysis of 2018 and 2019, including the manuscript preparation; D.F analyzed and interpreted "the bridge" between the community and government as a basis to make a strong advocacy and partnership, as well as writing them in the manuscript; A.P. and W.G.P. were involved in the preparation of the mobile app development including writing the method in the manuscript. They also prepared server data quality, performed back-end analysis, built website for admin, and interpreted function needed from community and government. All authors have read and approved the manuscript.

\section{Acknowledgements}

The authors acknowledge Puskesmas Pasawahan, Purwakarta district, West Java Indonesia for facilitating the community work and research in Posyandu, Purwakarta district health office for permission of conducting the research, Professor Ramdan Panigoro from Department of Biomedical Sciences, Faculty of Medicine, Universitas Padjadjaran Indonesia for leading and facilitating preliminary basis for the research in 2016 on the community education and research activities performed by students and lecturers, Gilang Abdul Aziz for contributing his expertise on the development of the mobile application. We also acknowledge Injury Working Group, Health System Research Centre, Faculty of Medicine, Universitas Padjadjaran Indonesia, for the permission of using STATA Special Edition 15.1 license.

\section{Authors' information}

${ }^{1}$ Department of Public Health, Faculty of Medicine, Universitas Padjadjaran, Jl. Eyckman No. 38, Bandung 40161, West Java, Indonesia. ${ }^{2}$ Center for Health System Study and Health Workforce Education Innovation, Faculty of Medicine, Universitas Padjadjaran, Jl. Eyckman No. 38, Bandung 40161, West Java, Indonesia. ${ }^{3}$ Mother and Child Health Division, Department of Public Health, Faculty of Medicine, Universitas Padjadjaran, Jl. Eyckman No. 38, Bandung 40161, West Java, Indonesia. ${ }^{4}$ Biostatistics and Epidemiology Division, Department of Public Health, Faculty of Medicine, Universitas Padjadjaran, Jl. Eyckman No. 38, Bandung 40161, West Java, Indonesia. ${ }^{5}$ Midwifery Master Study Program, Faculty of Medicine, Universitas Padjadjaran, Jl. Eyckman No. 38, Bandung 40161, West Java, Indonesia. ${ }^{6}$ Informatics Engineering Study Program, Faculty of Engineering, Universitas Pasundan, JI. Dr. Setiabudi No.193, Bandung 40153, West Java, Indonesia.

\section{References}

1. Fonda SJ, Kedziora RJ, Vigersky RA, Bursell SE. Combining iGoogle and personal health records to create a prototype personal health application for diabetes self-management. Telemed J E Health. 2010;16(4):480-9.

2. Källander K, Tibenderana KJ, Akpogheneta JO, Strachan LD, Hill Z, ten Asbroek AAH, et al. Mobile Health (mHealth) Approaches and lessons for increased performance and retention of community health workers in low- and middle-income countries: a review. J Med Internet Res. 2013;15(1):e17.

3. Rifkin SB. Examining the links between community participation and health outcomes: a review of the literature. Health Policy and Planning. 2014;29(suppl_2):ii98-ii106.

4. Walji N. Leadership: An action research approach. Ai \& Society. 2009;23(1):69-84.

5. Braun R, Catalani C, Wimbush J, Israelski D. Community Health Workers and Mobile Technology: A Systematic Review of the Literature. PLOS ONE. 2013;8(6):e65772.

6. Silva BMC, Rodrigues JJPC, de la Torre Díez I, López-Coronado M, Saleem K. Mobile-health: A review of current state in 2015. Journal of Biomedical Informatics. 2015;56:265-72.

7. Payne HE, Lister C, West JH, Bernhardt JM. Behavioral Functionality of Mobile Apps in Health Interventions: A Systematic Review of the Literature. JMIR mHealth and uHealth. 2015;3(1):e20.

8. Agarwal S, Perry HB, Long LA, Labrique AB. Evidence on feasibility and effective use of mHealth strategies by frontline health workers in developing countries: systematic review. Tropical medicine \& international health : TM \& IH. 2015;20(8):1003-14.

9. Feroz A, Jabeen R, Saleem S. Using mobile phones to improve community health workers performance in low-and-middle-income countries. BMC Public Health. 2020;20(1):49.

10. Early J, Gonzalez C, Gordon-Dseagu V, Robles-Calderon L. Use of Mobile Health (mHealth) Technologies and Interventions Among Community Health Workers Globally: A Scoping Review. Health Promotion Practice. 2019;20(6):805-17.

11. Amoakoh-Coleman M, Borgstein AB-J, Sondaal SFV, Grobbee DE, Miltenburg AS, Verwijs M, et al. Effectiveness of mHealth Interventions Targeting Health Care Workers to Improve Pregnancy Outcomes in Low- and Middle-Income Countries: A Systematic Review. Journal of Medical Internet Research. 2016;18(8):e226.

12. Nazri C, Yamazaki C, Kameo S, Herawati DMD, Sekarwana N, Raksanagara A, et al. Factors influencing mother's participation in Posyandu for improving nutritional status of children under-five in Aceh Utara district, Aceh province, Indonesia. BMC Public Health. 2016;16(1):69.

13. Pallas SW, Minhas D, Pérez-Escamilla R, Taylor L, Curry L, Bradley EH. Community Health Workers in Low- and Middle-Income Countries: What Do We Know About Scaling Up and Sustainability? American Journal of Public Health. 2013;103(7):e74-e82.

14. Sonderman KA, Nkurunziza T, Kateera F, Gruendl M, Koch R, Gaju E, et al. Using mobile health technology and community health workers to identify and refer caesarean-related surgical site infections in rural Rwanda: a randomised controlled trial protocol. BMJ open. 2018;8(5):e022214. 
15. O'Connor Y, Hardy V, Heavin C, Gallagher J, O’Donoghue J, editors. Supporting LIFE: Mobile health application for classifying, treating and monitoring disease outbreaks of sick children in developing countries. International conference on design science research in information systems; 2015: Springer.

16. Little A, Medhanyie A, Yebyo H, Spigt M, Dinant G-J, Blanco R. Meeting community health worker needs for maternal health care service delivery using appropriate mobile technologies in Ethiopia. PloS one. 2013;8(10):e77563-e.

17. Allsop MJ, Powell RA, Namisango E. The state of mHealth development and use by palliative care services in sub-Saharan Africa: a systematic review of the literature. BMJ Supportive \&amp; Palliative Care. 2018;8(2):155-63.

18. Namisango E, Ntege C, Luyirika EBK, Kiyange F, Allsop MJ. Strengthening pharmaceutical systems for palliative care services in resource limited settings: piloting a mHealth application across a rural and urban setting in Uganda. BMC Palliative Care. 2016;15(1):20.

19. Arisanti N, Sasongko EPS, Pandia V, Hilmanto D. Implementation of palliative care for patients with terminal diseases from the viewpoint of healthcare personnel. BMC Research Notes. 2019;12(1):217.

20. Gilmore B, McAuliffe E. Effectiveness of community health workers delivering preventive interventions for maternal and child health in low- and middleincome countries: a systematic review. BMC Public Health. 2013;13(1):847.

21. WHO, UNICEF. WHO/UNICEF joint statement: integrated community case management (iCCM). 2012.

22. Labrique AB, Vasudevan L, Kochi E, Fabricant R, Mehl G. mHealth innovations as health system strengthening tools: 12 common applications and a visual framework. Global Health: Science and Practice. 2013;1(2):160-71.

23. Anwar F, Khomsan A, Sukandar D, Riyadi H, Mudjajanto ES. High participation in the Posyandu nutrition program improved children nutritional status. Nutr Res Pract. 2010;4(3):208-14.

24. Creswell JW, Creswell JD. Research design: Qualitative, quantitative, and mixed methods approaches. Fifth ed: Sage publications; 2018.

25. Banerjee I, Nguyen B, Garousi V, Memon A. Graphical user interface (GUI) testing: Systematic mapping and repository. Information and Software Technology. 2013;55(10):1679-94.

26. Park K-G, Han S, Kaid LL. Does social networking service usage mediate the association between smartphone usage and social capital? New Media \& Society. 2013;15(7):1077-93.

27. Bisallah Cl, Rampal L, Lye M-S, Sidik SM, Ibrahim N, Iliyasu Z, et al. Effectiveness of health education intervention in improving knowledge, attitude, and practices regarding Tuberculosis among HIV patients in General Hospital Minna, Nigeria-A randomized control trial. PloS one. 2018;13(2).

28. Hulley SB, et al. Designing Clinical Research. 3rd ed: Lippincott Williams \& Wilkins; 2007.

29. Field A. Discovering statistics using IBM SPSS statistics: North American edition: Sage; 2017.

30. Pallant J. SPSS Survival Guide Manual 6th edition. Two Penn Plaza. New York, NY: McGraw Hill Education; 2016.

31. Brydon-Miller M, Greenwood D, Maguire P. Why action research? Action research. 2003;1(1):9-28.

32. Musselwhite C, Freeman S, Marston HR. Transcendent Technology and Mobile eHealth. Mobile e-Health: Springer; 2017. p. $299-306$.

33. de Beurs D, van Bruinessen I, Noordman J, Friele R, van Dulmen S. Active involvement of end users when developing web-based mental health interventions. Frontiers in psychiatry. 2017;8:72.

34. Walsh DM, Moran K, Cornelissen V, Buys R, Claes J, Zampognaro P, et al. The development and codesign of the PATHway intervention: a theory-driven eHealth platform for the self-management of cardiovascular disease. Translational behavioral medicine. 2018.

35. Still B, Crane K. Fundamentals of user-centered design: A practical approach: CRC Press; 2017.

36. Palinkas LA, Mendon SJ, Hamilton AB. Innovations in mixed methods evaluations. Annual review of public health. 2019;40:423-42.

37. Mangwi Ayiasi R, Atuyambe LM, Kiguli J, Orach CG, Kolsteren P, Criel B. Use of mobile phone consultations during home visits by Community Health Workers for maternal and newborn care: community experiences from Masindi and Kiryandongo districts, Uganda. BMC Public Health. 2015;15(1):560.

38. Aranda-Jan CB, Mohutsiwa-Dibe N, Loukanova S. Systematic review on what works, what does not work and why of implementation of mobile health (mHealth) projects in Africa. BMC Public Health. 2014;14(1):188.

39. Kouadio IK, Ghazi HF, Maimaiti N, Rahimi A, Aljunid SM. Potential of mobile technology in meeting the public health needs in developing countries. BMC Public Health. 2012;12(2):A13.

40. Puri S, Fernandez S, Puranik A, Anand D, Gaidhane A, Quazi Syed Z, et al. Policy content and stakeholder network analysis for infant and young child feeding in India. BMC Public Health. 2017;17(2):461.

41. Basu P, Mahajan M, Patira N, Prasad S, Mogri S, Muwonge R, et al. A pilot study to evaluate home-based screening for the common non-communicable diseases by a dedicated cadre of community health workers in a rural setting in India. BMC Public Health. 2019;19(1):14.

42. Plowright A, Taylor C, Davies D, Sartori J, Hundt GL, Lilford RJ. Formative evaluation of a training intervention for community health workers in South Africa: A before and after study. PloS one. 2018;13(9).

43. Armaou M, Araviaki E, Musikanski L. eHealth and mHealth Interventions for Ethnic Minority and Historically Underserved Populations in Developed Countries: an Umbrella Review. International Journal of Community Well-Being. 2019:1-29.

44. Sabo S, Flores M, Wennerstrom A, Bell ML, Verdugo L, Carvajal S, et al. Community Health Workers Promote Civic Engagement and Organizational Capacity to Impact Policy. Journal of Community Health. 2017;42(6):1197-203.

45. Olushola T, Abiola J. The efficacy of technology acceptance model: A review of applicable theoretical models in information technology researches. Journal of Research in Business and Management. 2017;4(11):70-83.

46. Magsamen-Conrad K, Upadhyaya S, Joa CY, Dowd J. Bridging the divide: Using UTAUT to predict multigenerational tablet adoption practices. Computers in human behavior. 2015;50:186-96.

Page $13 / 16$ 
47. Dwivedi YK, Rana NP, Jeyaraj A, Clement M, Williams MD. Re-examining the unified theory of acceptance and use of technology (UTAUT): Towards a revised theoretical model. Information Systems Frontiers. 2019;21(3):719-34.

48. Marangunić N, Granić A. Technology acceptance model: a literature review from 1986 to 2013. Universal Access in the Information Society. 2015;14(1):8195.

49. Lai P. The literature review of technology adoption models and theories for the novelty technology. JISTEM-Journal of Information Systems and Technology Management. 2017;14(1):21-38.

50. Lee SH, Nurmatov UB, Nwaru BI, Mukherjee M, Grant L, Pagliari C. Effectiveness of mHealth interventions for maternal, newborn and child health in lowand middle-income countries: Systematic review and meta-analysis. Journal of Global Health. 2016;6(1):010401.

51. Holipah, Maharani A, Kuroda Y. Determinants of immunization status among 12- to 23-month-old children in Indonesia (2008-2013): a multilevel analysis. BMC Public Health. 2018;18(1):288.

52. Ministry of National Development Planning. Guideline on stunting integrated intervention in districts/cities. 2018.

http://tnp2k.go.id/filemanager/files/Rakornis\%202018/Pedoman\%20Pelaksanaan\%20Intervensi\%20Penurunan\%20Stunting\%20Terintegrasi\%20Di\%20Ka (accessed on 24 May 2020)

53. Ministry of Health. Guideline on integrated nutrition information system. 2019. http://sigiziterpadu.gizi.kemkes.go.id/ (accessed 11 May 2020 )

54. Smisha A, B. PH, Lesley-Anne L, B. LA. Evidence on feasibility and effective use of mHealth strategies by frontline health workers in developing countries: systematic review. Tropical Medicine \& International Health. 2015;20(8):1003-14.

55. Chib A, van Velthoven MH, Car J. mHealth Adoption in Low-Resource Environments: A Review of the Use of Mobile Healthcare in Developing Countries. Journal of Health Communication. 2015;20(1):4-34.

56. Kallander K, Tibenderana JK, Akpogheneta OJ, Strachan DL, Hill Z, ten Asbroek AH, et al. Mobile health (mHealth) approaches and lessons for increased performance and retention of community health workers in low- and middle-income countries: a review. J Med Internet Res. 2013;15(1):e17.

57. Iyengar S. Chapter 12 - Mobile health (mHealth). In: Gogia S, editor. Fundamentals of Telemedicine and Telehealth: Academic Press; 2020. p. $277-94$.

58. Costello A, Peterson S, Rasanathan K, Daelmans B, Bahl R. Where's the leadership? Future commitments of Unicef and WHO for global child health. BMJ. 2018;362:k3219.

59. Faridah L, Rinawan FR, Fauziah N, Mayasari W, Dwiartama A, Watanabe K. Evaluation of Health Information System (HIS) in The Surveillance of Dengue in Indonesia: Lessons from Case in Bandung, West Java. International Journal of Environmental Research and Public Health. 2020;17(5):1795.

\section{Figures}

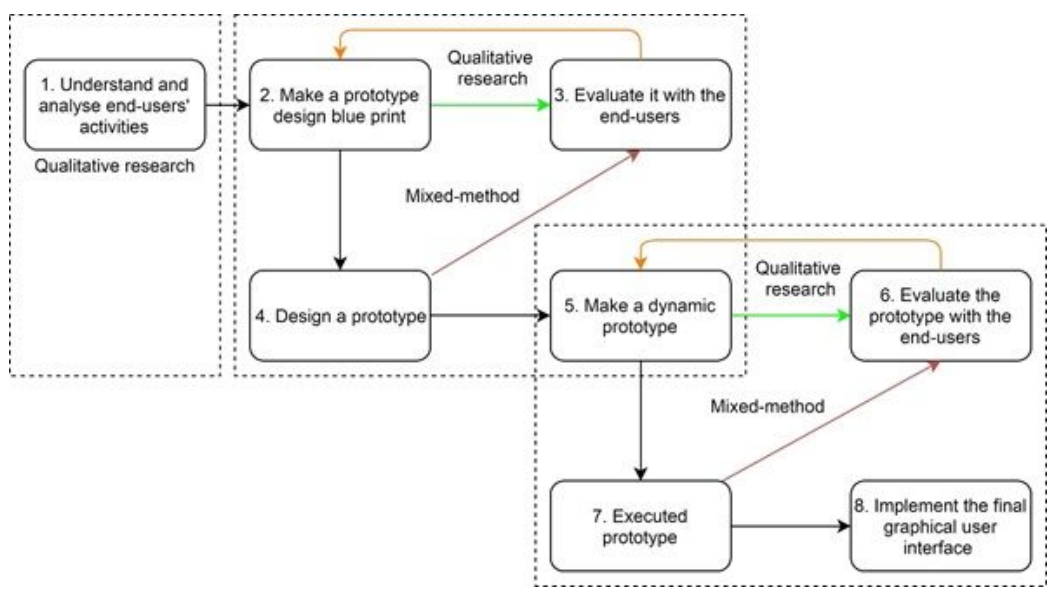

Figure 1

Hybrid approach (action research principal and mixed-method research design) to develop Posyandu application 


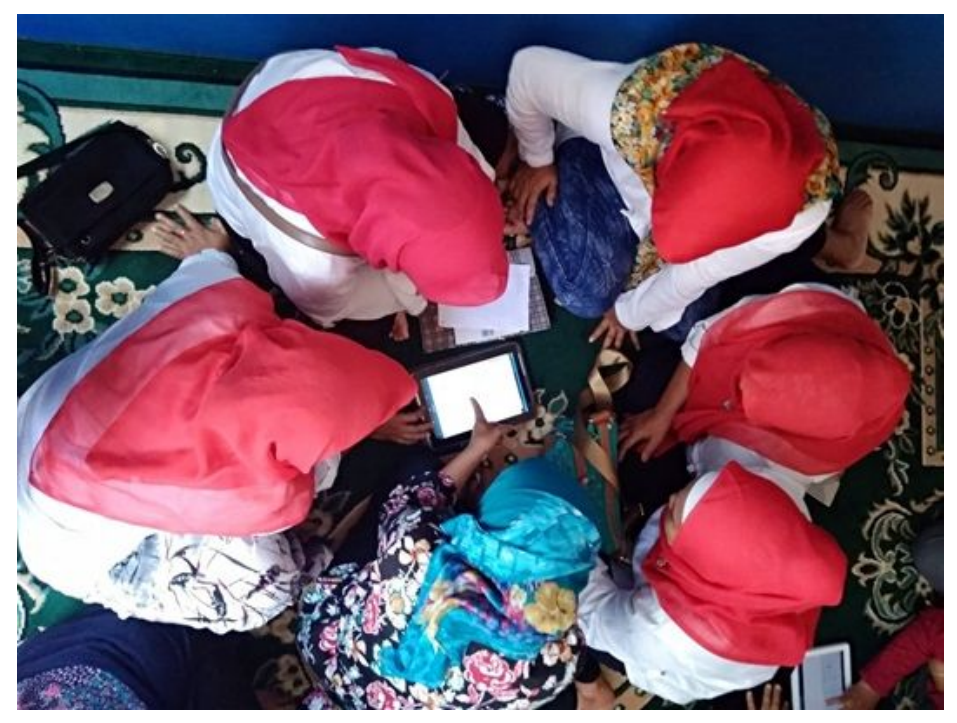

\section{Figure 2}

The process of Focus Group Discussion for a dynamic evaluation and execution of Posyandu application

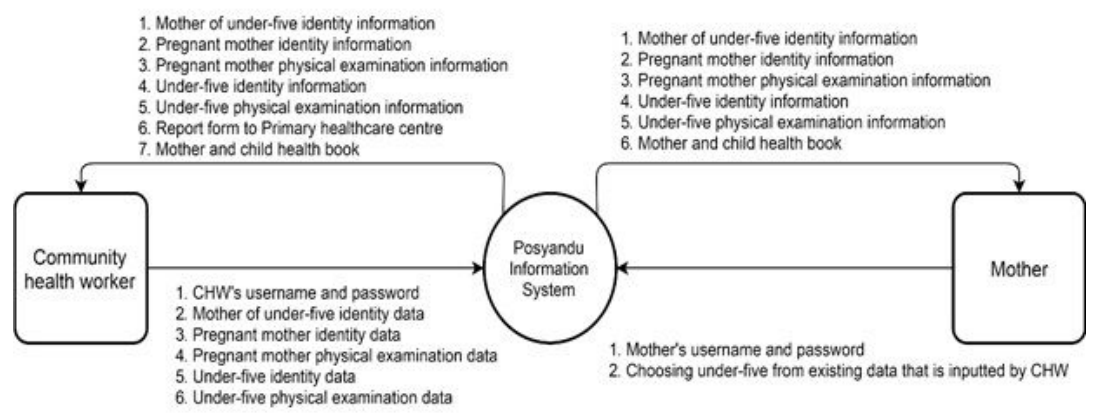

\section{Figure 3}

Data flow diagram of mobile health application design in Posyandu information system
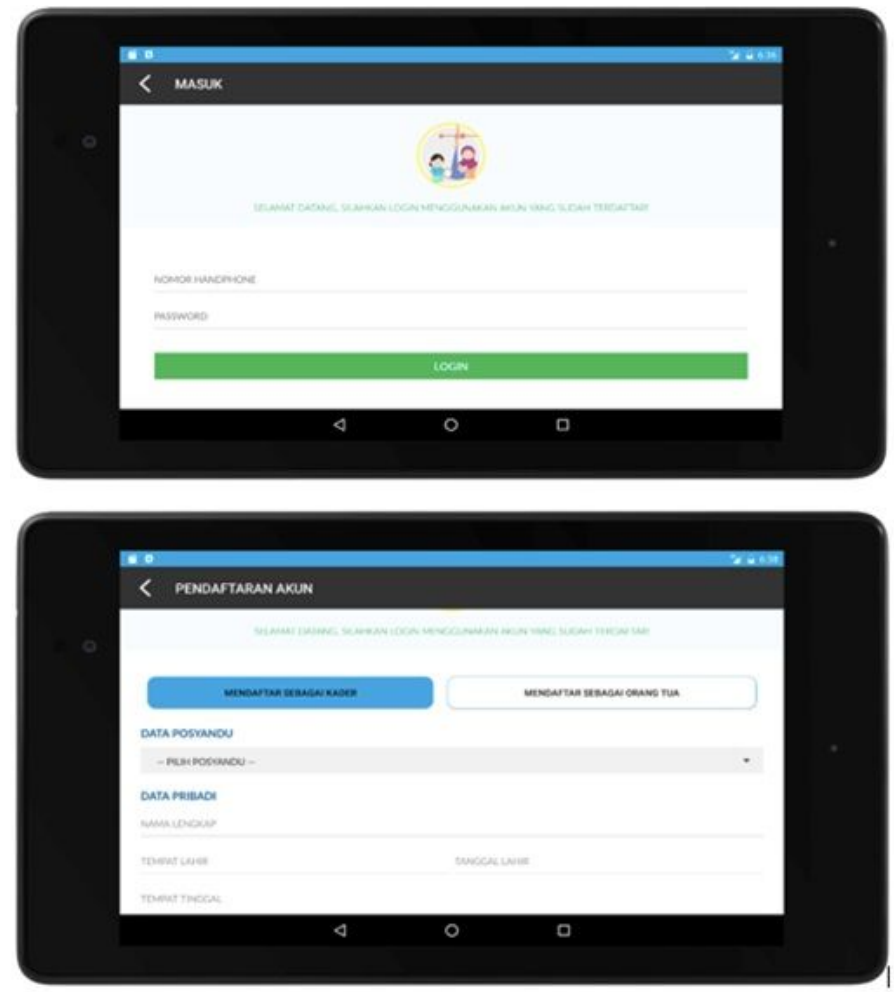

Figure 4 
2019

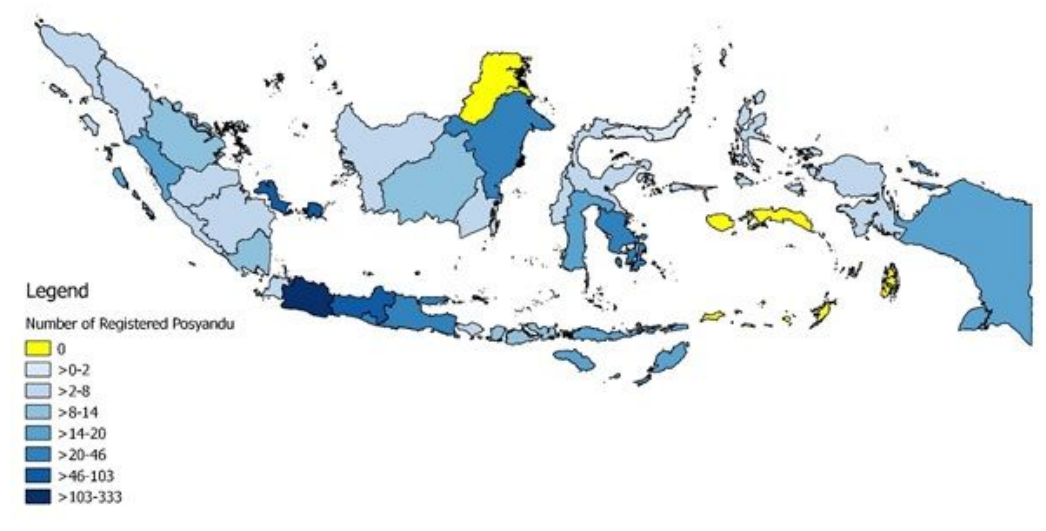

Figure 5

Distribution of registered Posyandu in the mobile app in Indonesia until 31 December 2019

\section{Supplementary Files}

This is a list of supplementary files associated with this preprint. Click to download.

- SupplementalMaterials.pdf 